\title{
ASPEK PERTUMBUHAN UNDUR-UNDUR LAUT, Hippa adactyla DARI PANTAI BERPASIR KABUPATEN KEBUMEN
}

\author{
Ali Mashar* dan Yusli Wardiatno \\ Departemen Manajemen Sumberdaya Perairan, Fakultas Perikanan dan Ilmu Kelautan, \\ Institut Pertanian Bogor \\ *penulis untuk korespondensi: alimashar75@gmail.com
}

\begin{abstract}
ABSTRAK
Undur-undur laut atau mole crab merupakan komponen penting dari komunitas makrobentos di pantai berpasir terbuka, baik di daerah tropis maupun bermusim empat di seluruh dunia.Undur-undur laut mempunyai fungsi ekonomi dan ekologi.Salah satu jenis undur-undur laut yang banyak dijumpai di Indonesia adalah jenis Hippa adactyla.Karena fungsi ekonomi dan ekologi undur-undur laut penting untuk dilestarikan, salah satu informasi penting yang dibutuhkan adalah pola pertumbuhan undurundur laut.Penelitian dilakukan di Pantai Bocor, Kecamatan Buluspesantren, Kabupaten Kebumen.Pengambilan sampel undur-undur laut dilakukan setiap bulan dari bulan Maret hingga Mei 2012, yang dilakukan dengan metode penyapuan dengan bantuan alat tangkap sorok pada daerah pantai berpasir yang terpengaruh gerakan gelombang (swash zone) (swept area method).Hasil penelitian menunjukkan bahwa undur-undur laut Hippa adactyla yang tertangkap mempunyai kisaran panjang karapas antara $15 \mathrm{~mm}$ hingga $40 \mathrm{~mm}$, dengan ukuran yang paling banyak tertangkap berada pada selang panjang karapas 24-26 mm.Nisbah kelamin undur-undur laut di lokasi penelitian mendekati $1(1,035)$ atau tergolong seimbang, dimana jumlah undur-undur laut jantan relatif seragam dengan undur-undur laut betina.Kondisi ini juga menunjukkan bahwa kondisi populasi undur-undur laut di lokasi penelitian relatif stabil. Pola pertumbuhan undur-undur laut Hippa adactylaseluruhnya, baik jantan, betina, maupun gabungan, adalah isometrik, artinya pertambahan panjang undur-undur laut relatifsama dengan pertambahan bobotnya.
\end{abstract}

Kata kunci: Hippa adactyla, pantai berpasir, undur-undur laut

\begin{abstract}
Mole crabs are one of important biological component among macrobenthos community inhabiting sandy beach, both in tropic or temperate area all over the world. They play significant ecology and economy role in their habitat. One of Indonesian mole crabs is Hippa adactyla. Due to its ecological and economical function of the crab, it is neede to study the population growth pattern for biological information based sustainable management. One of important biological information is growth pattern. The research was conducted in Pantai Bocor, Kecamatan Buluspesantren, Kabupaten Kebumen. Sample collections were done monthly during March - May 2012. Sampling was done by swep area method by means of local fishermen gear called sorok along swash zone. The results showed that the carapace length of collected crabs ranged from $19-34 \mathrm{~mm}$, with the highest abundance within range of $29-30 \mathrm{~mm}$. Female dominated the sex ratio. The F/M ratio was 0.244 . The growth pattern of male was isometric, while in female it was negative allometric. However, combining data showed that the growth patern of the population was negative allometric, so its length grows faster than its weight.
\end{abstract}

Keywords: Hippa adactyla, sandy beach, mole crab, southern part of Jawa 


\section{PENDAHULUAN}

$\mathrm{U}$ ndur-undur laut atau mole crab merupakan komponen penting dari komunitas makrobentos di pantai berpasir terbuka, baik di daerah tropis maupun bermusim empat di seluruh dunia (Efford 1976; Trueman 1970; Trueman \& Ansell 1969; Haley 1982; Dugan et al. 1995, Dugan et al. 2000 ab, 2003, Lastra et al. 2002).Pesisir Indonesia juga merupakan salah satu daerah sebaran undurundur laut, terutama untuk undur-undur laut famili Hippidae, diantaranya di pesisir Kabupaten Kebumen. Salah satu jenis undur-undur laut yang dijumpai di pantai berpasir Kabupaten Kebumen adalah jenis Hippa adactyla, yang dikenal juga dengan nama lokal "yutuk batok".

Secara umum, undur-undur laut di wilayah pesisir Jawa Tengah, termasuk pesisir Kabupaten Kebumen, banyak dimanfaatkan sebagai makanan atau jajanan ringan bagi para pengunjung pantai, dan telah menjadi mata pencaharian bagi beberapa penduduk di sekitar pantai.Undur-undur laut ini juga dapat menjadi alternatif bahan campuran yang baik untuk pakan hewan ternak, yaitu itik, karena telur itik yang dihasilkan dari itik yang diberi pakan dengan ditambahkan tepung yutuk memiliki kandungan omega-3 lebih tinggi dan warna kuning telur lebih oranye atau oranye tua (Hartono et al. 2010).

Disamping nilai ekonomi, undur-undur laut juga memiliki nilai ekologi yang cukup penting di perairan intertidal, yaitu berperan dalam siklus atau rantai makanan di daerah intertidal sebagai consumer tingkat pertama, dan sebagai indikator lingkungan perairan daerah intertidal, yaitu sebagai bioindikator pencemaran pestisida atau DDT, tumpahan minyak, merkuri, dan indikasi kandungan asam domoik (neurotoksin yang dihasilkan oleh diatom) (Siegel \& Wenner 1984, Wenner 1988; Pérez 1999; Mann 2000; Dugan et al. 2005).

Seiring dengan semakin banyak masyarakat mengenal nilai ekonomi undur-undur laut, terutama di Kabupaten Kebumen, maka semakin banyak masyarakat pesisir penangkap undurundur laut.Kondisi tersebut berdampak pada tekanan yang makin tinggi pada populasi dan habitat undur-undur laut.Oleh karena itu, perlu dilakukan langkah pengelolaan yang tepat dan bijak dalam pemanfaatan undur-undur laut agar populasi undur-undur laut tetap lestari, baik secara ekonomi maupun ekologi.Salah satu informasi penting sebagai dasar untuk pengelolaan undur-undur laut tersebut adalah informasi tentang pola pertumbuhan undur-undur laut. Penelitian ini bertujuan untuk mengetahui pola pertumbuhan undur-undur laut jenis Hippa adactyla.

\section{BAHAN DAN METODE}

\section{Waktu dan Lokasi Penelitian}

Penelitian dilakukan pada bulan Maret hingga Mei 2012 di pantai berpasir, Kecamatan Buluspesantren,Kabupaten Kebumen, Jawa Tengah (Gambar 1). Pengambilan sampel dilakukan sebulan sekali.Analisis laboratorium dilakukan di LaboratoriumBiologi Mikro 1, Departemen Manajemen Sumber Daya Perairan, Fakultas Perikanandan Ilmu Kelautan, Institut Pertanian Bogor. 


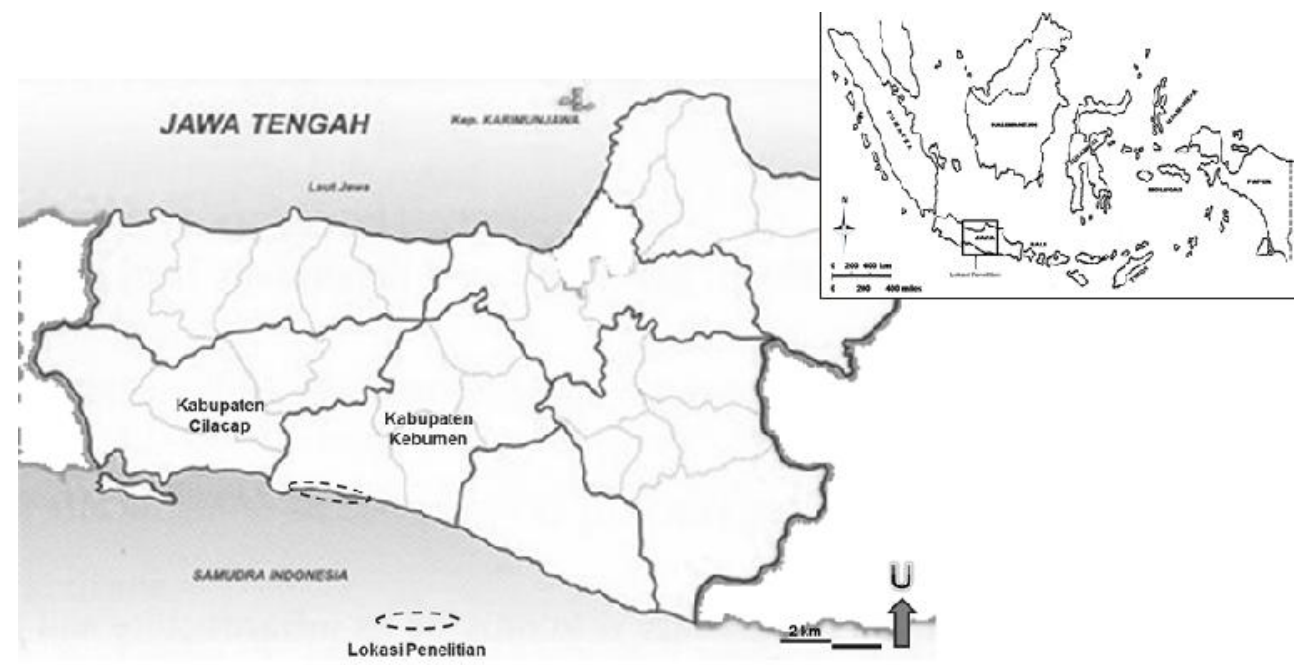

Gambar 1. Peta Lokasi Penelitian

\section{Pengambilan dan Penanganan Sampel}

Sampel undur-undur laut dikumpulkan dengan metode sapuan pada kawasan berpasir di pantai yang basah akibat gerakan gelombang (swash zone) (swept area method), dengan bantuan alat berupa alat tangkap sorok yang biasa digunakan nelayan setempat.Sampel undur-undur laut yang tertangkap ditempatkan di dalam wadah dari plastik klip dan/atau botol plastik.Kemudian diawetkan dengan formalin 10\%. Pengukuran panjang karapas dan bobot total (bobot basah) undur-undur laut dilakukan di laboratorium. Jumlah undur-undur laut Hippa adactyla yang tertangkap selama penelitian berjumlah 219 ekor, terdiri atas 43 ekor jantan dan 176 ekor betina (Gambar 2).

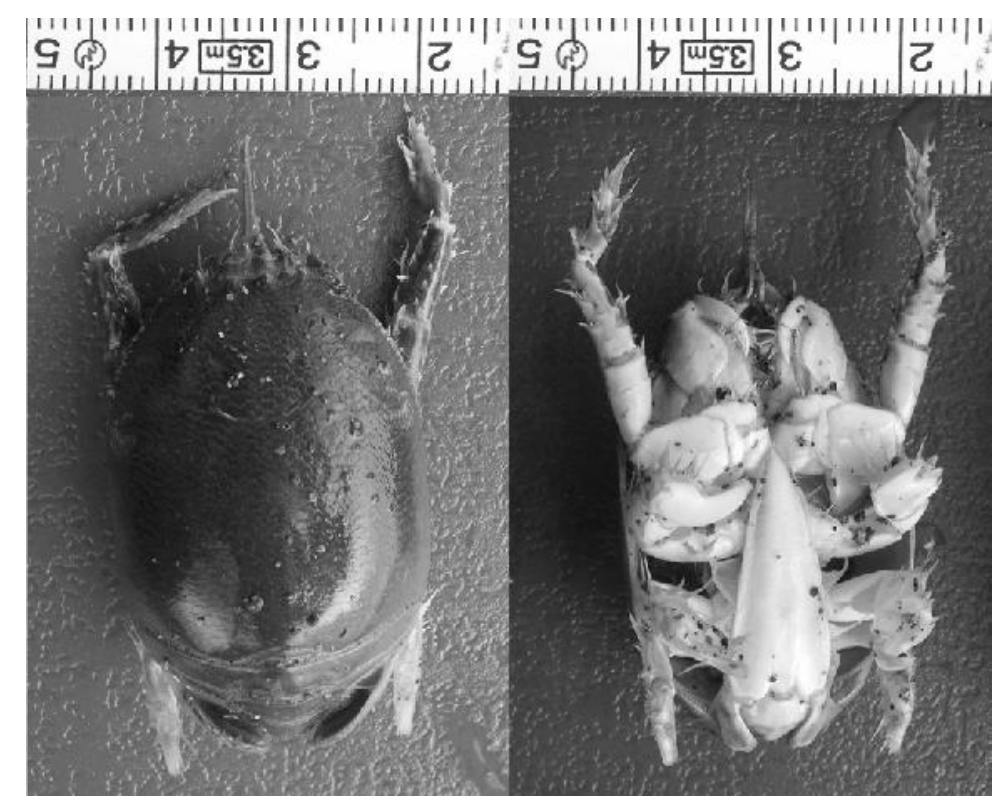

Gambar 2. Undur-undur Laut Jenis Hippa adactyla yang Ditemukan di Lokasi Penelitian 


\section{Analisis Data}

Data yang dianalisis adalah pola pertumbuhan undur-undur laut berdasarkan informasi sebaran frekuensi panjang karapas, nisbah kelamin, dan hubungan panjang karapasdengan bobot total undur-undur laut.

\section{Sebaran frekuensi panjang}

Sebaran frekuensi panjang dapat dianalisis menggunakan data panjangundur-undur laut yang telah diukur. Adapun analisis data frekuensi panjang menurut Walpole (1992) dapat dilakukan dengan langkah-langkah sebagai berikut:

a. Menentukan jumlah selang kelas yang diperlukan

b. Menentukan lebar kelas

c. Menentukan kelas frekuensi dan memasukkan masing-masing kelas denganmemasukkan panjang dan bobot masing-masing biota contoh pada selang kelas yangtelah ditentukan.

d. Sebaran frekuensi panjang yang didapatkan kemudian diplotkan ke dalam sebuahgrafik.

\section{Nisbah kelamin}

Nisbah kelamin (sex ratio) merupakan perbandingan jumlah undur-undur laut jantan dibanding dengan betina.Idealnya, untuk populasi di alam, rasionyaadalah 1 , artinya 1 jantan untuk 1 betina.Sex ratio hanya membandingkanjumlah jantan dengan jumlah betina yang tertangkap di setiap bulannya.Untuk menguji apakah rasionya seimbang (1:1) atau tidak diantara kedua jenis kelamin, maka digunakan uji statistik Chikuadrat $\left(\chi^{2}\right)$ sebagai berikut (Steel and Torrie 1993):

$$
\chi^{2}=\sum_{\mathrm{i}=1}^{\mathrm{n}} \frac{\left(\mathrm{o}_{\mathrm{i}}-\mathrm{e}_{\mathrm{i}}\right)^{2}}{\mathrm{e}_{\mathrm{i}}}
$$

Keterangan:

$\chi^{2}=$ nilai peubah acak $\chi^{2}$ yang sebaran penarikan contohnya mendekati sebaran Chi-kuadrat

$o_{i}=$ jumlah frekuensi undur-undur laut jantan dan betina ke-i yang diamati

$\mathrm{e}_{\mathrm{i}}=$ jumlah frekuensi harapan dari undurundur laut jantan dan betina, yaitu frekuensi undur-undur laut jantan ditambah frekuensi undur-undur laut betina dibagi dua

\section{Hubungan panjang karapas dengan bobot total}

Hubungan panjang bobot digambarkan dengan $\mathrm{W}$ $=\mathrm{aL}^{\mathrm{b}}$, dimana a dan badalah konstanta yang didapatkan dari perhitungan regresi, sedangkan $\mathrm{W}$ adalahbobot dan $\mathrm{L}$ adalah panjang.Bilamana nilai $\mathrm{n}=3$ menunjukkan bahwa pertumbuhan undur-undur laut tidak berubah bentuknya disebut dengan pertumbuhan isometrik. Jika $3<b<3$ dinamakan pertumbuhan allometrik.Apabila nilai $b<3$ menunjukkan keadaan pertambahan panjangnya lebih cepat dari pertambahan bobotnya, sementara itu, jika nilai $b$ $>3$ menunjukkan pertambahanbobot lebih cepat dari pertambahan panjangnya (Effendie 2005).

\section{HASIL DAN PEMBAHASAN}

\section{Sebaran Frekuensi Panjang}

Sebaran frekuensi panjang merupakan sebaran jumlah undur-undur laut pada setiap selang kelas panjang yang dihitung per satuan panjang karapas undur-undur laut.Secara ringkas, sebaran frekuensi panjang Hippa adactyladisajikan pada Gambar 3. 


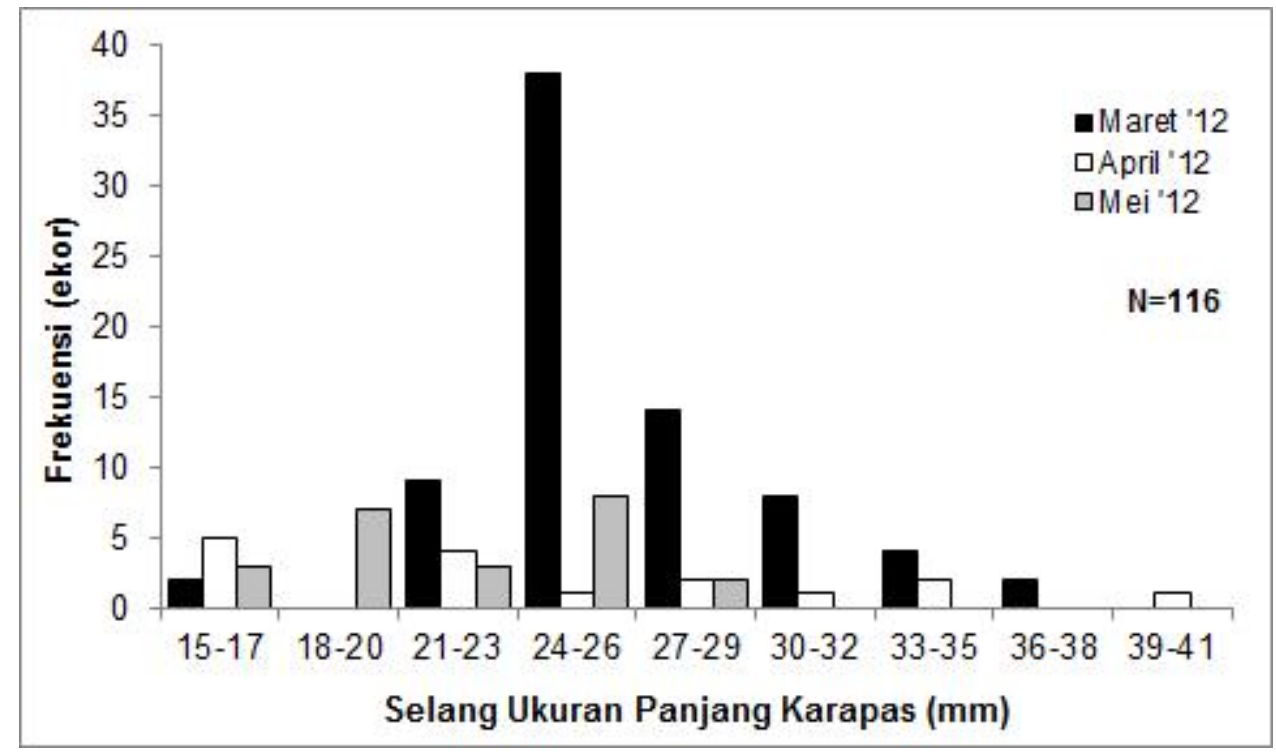

Gambar 3. Sebaran Frekuensi Panjang Hippa adactyla

Gambar 3 menunjukkan bahwa berdasarkan ukuran panjang karapas, dari total 116 ekor yang didapatkan selama penelitian, ukuran panjang karapas undur-undur laut Hippa adactyla tampak menyebar normal dari ukuran $15 \mathrm{~mm}$ hingga 41 $\mathrm{mm}$, dimana paling banyak ditemukan pada selangkelas panjang 24-26 mm.Berdasarkan gambar di atas juga terlihat bahwa pada bulanbulan pengamatan tidak ada yang dijumpai seluruh ukuran kelas panjang karapas.

\section{Nisbah Kelamin}

Nisbah kelamin merupakan perbandingan jumlah undur-undur laut jantandibandingkan dengan jumlah undur-undur laut betinanya.Nisbah kelamin Hippa adactyla disajikan pada Tabel 1.

Tabel 1. Nisbah Kelamin Hippa adactyla

\begin{tabular}{cccccc}
\hline Selang Kelas $(\mathbf{m m})$ & Jantan & Betina & Jantan/Betina & $\mathbf{X}^{\mathbf{2}}$ Hitung & $\mathbf{X}^{\mathbf{2}}$ Tabel \\
\hline $15-17$ & 4 & 1 & 4,000 & 1,80 & \\
$18-20$ & 1 & 6 & 0,167 & 3,57 & \\
$21-23$ & 12 & 5 & 2,400 & 2,88 & \\
$24-26$ & 29 & 19 & 1,526 & 2,08 & \\
$27-29$ & 7 & 12 & 0,583 & 1,32 & \\
$30-32$ & 3 & 7 & 0,429 & 1,60 & \\
$33-35$ & 3 & 4 & 0,750 & 0,14 & \\
$36-38$ & 0 & 2 & - & 2,00 & \\
$39-41$ & 0 & 1 & - & 1,00 & \\
Total & $\mathbf{5 9}$ & $\mathbf{5 7}$ & $\mathbf{1 , 0 3 5}$ & $\mathbf{0 , 0 3}$ & $\mathbf{3 , 8}$
\end{tabular}

Berdasarkan analisis chi-square terhadap nisbah betinanya.Idealnya, rasio populasi jantan dan kelamin diketahui bahwa nilaiX ${ }^{2}$ hitungpada seluruh selang kelas panjang karapas lebih kecil dibandingkan dengan nilai $X^{2}$ tabel.Ini menunjukkan bahwa pada undur-undur laut Hippa adactylatidak ada perbedaan secara nyata antara jumlah undur-undur laut jantandengan jumlah undur-undur laut betina.

Nisbah kelamin undur-undur laut merupakan perbandingan jumlah undur-undur laut jantan dan betina di alam adalah 1:1 artinya 1 ekor jantan untuk 1 ekor betina.Hal tersebut agar terjadi keseimbangan populasi berdasarkan jenis kelamin atau agar tidak terjadi dominansi jenis kelamin.Berdasarkan hasil analisis yangterlihat pada Tabel 1, perbandingan jantan dengan betina Hippa adactyladari bulan Maret sampai Mei 2012 relatif seimbang.Hal tersebut dapat dilihat dari rasio keseluruhan yang nilainya berada pada 
nilai 1 (1,035).Hal tersebut menunjukkan bahwa populasi undur-undur laut Hippa adactyla di lokasi penelitian dalam keadaan relatif stabil, berbeda dengan undur-undur laut jenis Emerita emeritus pada lokasi yang sama yang dalam keadaan tidak stabil.

\section{Hubungan Panjang Karapas dengan Bobot Total}

Perbandingan panjang dan bobot undur-undur laut jenis Hippa adactyladisajikan padaTabel 2 danGambar 4.

Tabel 2. Hubungan Panjang dan Berat Undur-undur Laut

\begin{tabular}{ccccc}
\hline $\begin{array}{c}\text { Jenis } \\
\text { Kelamin }\end{array}$ & $\begin{array}{c}\mathrm{N} \\
(\mathrm{ekor})\end{array}$ & $\begin{array}{c}\text { Persamaan Hubungan } \\
\text { Panjang-Berat }\end{array}$ & $\begin{array}{c}\text { Kisaran Nilai b } \\
(\alpha=0,05)\end{array}$ & $\begin{array}{c}\text { Pola } \\
\text { Pertumbuhan(Setelah } \\
\text { Dilakukan Uji t dan } \\
\alpha=0,05)\end{array}$ \\
\hline Jantan & 59 & $\begin{array}{c}\mathrm{W}= \\
0,0005 \mathrm{~L}^{2,779} \mathrm{R}^{2}=0,848 ; \\
\mathrm{r}=0,921\end{array}$ & $2,623-2,935$ & Isometrik \\
Betina & 57 & $\begin{array}{c}\mathrm{W}=0,0006 \mathrm{~L}^{2,769} \\
\mathrm{R}^{2}=0,891 ; \mathrm{r}=0,944 \\
\mathrm{~W}=0,0005 \mathrm{~L}^{2,837} \\
\mathrm{R}^{2}=0,869 ; \mathrm{r}=0,932\end{array}$ & $2,636-2,897$ & Isometrik \\
Gabungan & 116 & $2,734-2,941$ & Isometrik \\
\hline
\end{tabular}

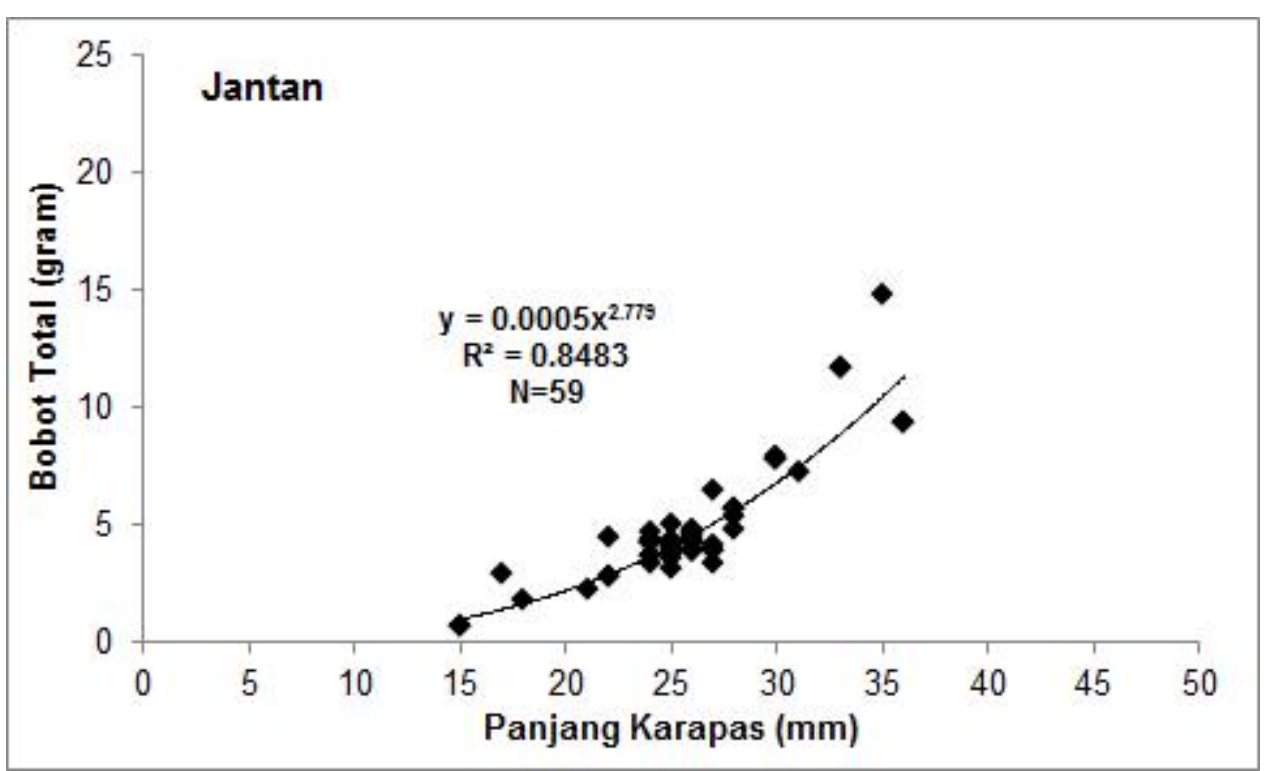



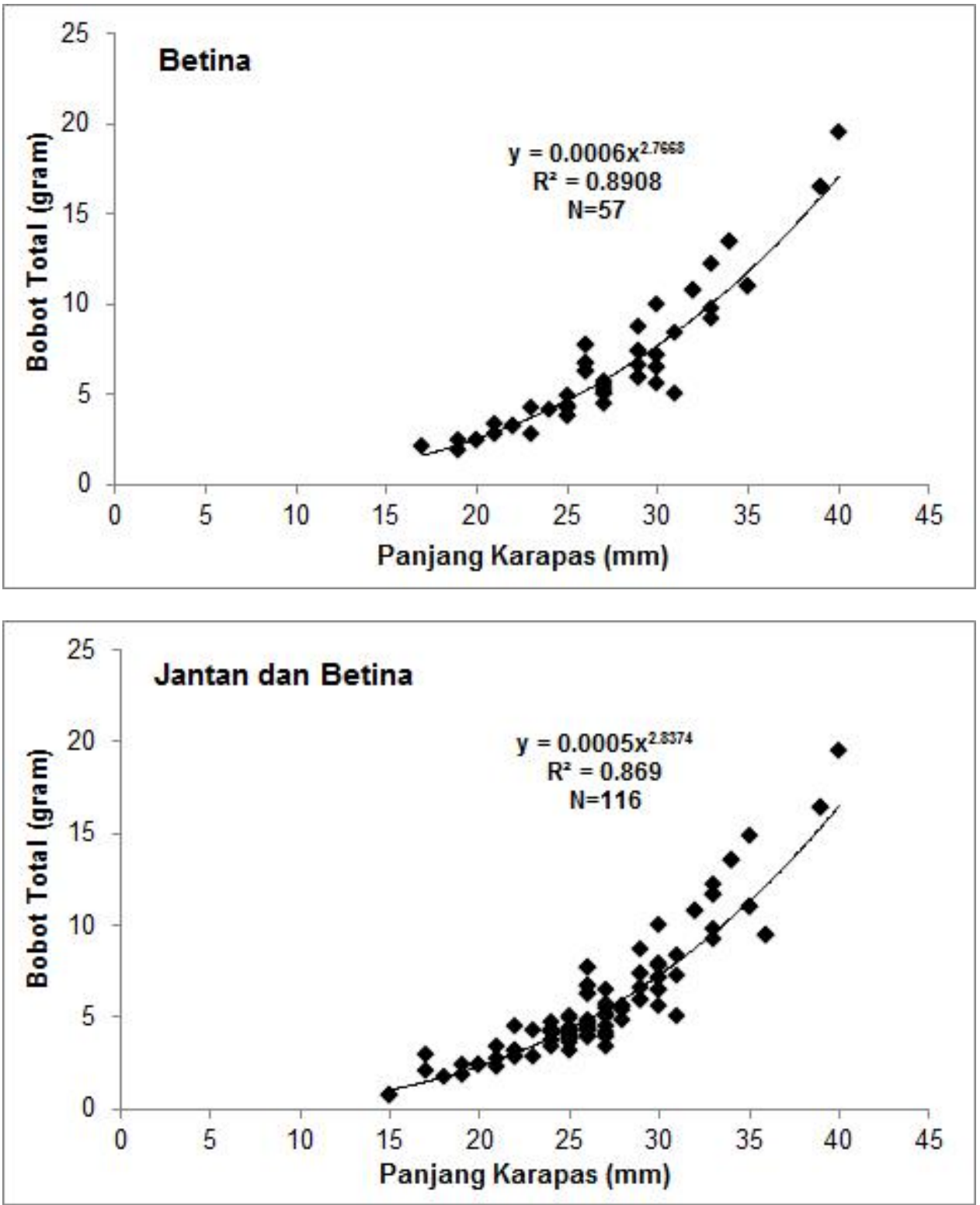

Gambar 4. Hubungan Panjang Karapas dan Bobot Hippa adactyla pada Jantan, Betina, dan Total (Jantan dan Betina)

Berdasarkan Tabel 3 dan Gambar 4 diketahui bahwa persamaan hubungan panjang bobot undur-undur lautsecara umum memiliki korelasi yang sangat erat.Hal tersebut didasarkan pada nilai koefesien korelasi (r)yang secara umum cenderung mendekati angka satu.Hal tersebut menunjukkan bahwa pertambahan panjang undur-undur laut diikuti dengan pertambahan bobot tubuhnya.Hal tersebut juga merupakan sifat umum dari krustasea yang biasanya mengalami perubahan bentuk tubuh selama tumbuh.

Berdasarkan Tabel 3 dan Gambar 4juga dapat dilihat bahwa pola pertumbuhan undur-undur laut jantan dan betina sama, yaitu isometrik. Walaupun secara nilai, koefisien pertumbuhan jantan dan betina nilainya $<3$, namun setelah dilakkan uji $t$, didapatkan nilai $t$ hitung lebih rendah dari nilai t tabel, sehingga gagal tolak H0.Artinya pola pertumbuhan undur-undur laut bukan alometrik, tetapi isometrik.Begitu juga ketika data undur-undur laut jantan dan betina digabung, pola pertumbuhannya juga tergolong isometrik.Artinya pertumbuhan panjang undurundur laut relatif sama dengan pertumbuhan bobotnya (Effendie 2005). 


\section{KESIMPULAN}

Ukuran panjang karapas undur-undur laut Hippa adactyla yang tertangkap selama penelitian berkisar antara $15 \mathrm{~mm}$ hingga $40 \mathrm{~mm}$. Ukuran Hippa adactyla yang banyak tertangkap selama penelitian adalah pada kisaran selang panjang 24$26 \mathrm{~mm}$. Nisbah kelamin undur-undur laut di lokasi penelitian nilainya mendekati angka 1 $(1,035)$ atau tergolong seimbang, dimana jumlah undur-undur laut jantan relatif seragam dengan undur-undur laut betina.Kondisi ini menunjukkan pula bahwa kondisi populasi undur-undur laut di lokasi penelitian relatif stabil.Pola pertumbuhan undur-undur laut Hippa adactylaseluruhnya, baik jantan, betina, maupun gabungan, adalah isometrik, artinya pertambahan panjang undurundur laut relatifsama dengan pertambahan bobotnya.

\section{DAFTAR PUSTAKA}

Dugan, JE, DM. Hubbard, dan HM. Page. 1995. Scaling population density to body size: tests in two soft sediment intertidal communities. J. Coast. Res. 11(3): 849857.

Dugan, JE, DM. Hubbard, JM. Engle, DL. Martin, DM. Richards, GE. Davis, KD. Lafferty, dan RF Ambrose. 2000 ${ }^{\mathrm{a}}$. Macrofauna communities of exposed sandy beaches on the Southern California mainland and Channel Islands. Fifth California Islands Symposium, OCS Study, MMS 99-0038: 339-346.

Dugan, JE, DM, Hubbard, dan M. Lastra. 2000 ${ }^{\mathrm{b}}$. Burrowing abilities and swash behavior of three crabs, Emerita analoga Stimpson, Blepharipoda occidentalis Randall and Lepidopa californica Efford (Anomura, Hippoidea), of exposed sandy beaches. $J$. Exp. Mar. Biol. Ecol. 255: 229-245.

Dugan, JE, DM. Hubbard, M. McCrary, dan M. Pierson. 2003. The response of macroinfauna communities and shorebirds to macrophyte wrack subsidies on exposed sandy beaches of southern California. Est. Coastl. Shelf Sci. 58S:133-148.

Effendi, MI. 2005. Biologi Perikanan. Yayasan Pustaka Nusantara:Yogyakarta.
Efford, I. 1976. Distribution of the sand crabs in the genus Emerita (Decapoda, Hippidae).Crustaceana 30, 169-183.

Haley, SR. 1982. Zonation by size of the Pacific mole crab, Hippa pacifica Dana (Crustacea: Anomura: Hippidae), in Hawaii. J. Exp. Mar. Biol. Ecol. 58, 221231.

Hartono, E, ES Rejeki, dan AA. Puspitasari. 2010. Pengaruh asupan makanan undurundur laut terhadap kandungan omega-3 pada telur itik. Fakultas Farmasi. Universitas Setia Budi. Surakarta.

Lastra, M, JE. Dugan, dan DM. Hubbard. 2002. Burrowing and swash behavior of the Pacific mole crab, Hippa pacifica (Anomura, Hippidae) on tropical sandy beaches. J. Crust. Biol., 22: 53-58.

Mann, KH. 2000. Sandy beaches. Ecology of Coastal Waters with Implications for Management. Volume 8 of Studies in Ecology ( $2^{\text {nd }}$ ed.). Wiley-Blackwell. pp. 218-236.

Pérez, D. 1999. Mercury levels in mole crabs Hippa cubensis, Emerita brasiliensis, E. portoricensis, and Lepidopa richmondi (Crustacea: Decapoda: Hippidae) from a sandy beach at Venezuela. Bull. Environ. Contam.Toxicol. 63:320-326.

Siegel, PR, dan AM. Wenner. 1984. Field and laboratory studies of sand crab growth. In: Wenner AM (ed.) Crustacean Growth, Crustacean Issues, Vol II. Balkema Press, Rotterdam.

Steel, RGD \& JH. Torrie. 1980. Principles and Procedures of Statistic. Diterjemahkan oleh Sumantri B. PT Gramedia. Jakarta. $772 \mathrm{p}$.

Trueman, ER. 1970. The mechanism of burrowing of the mole crab, Emerita. J. Exp. Biol. 53: 701-710.

Trueman, ER. dan AD. Ansell. 1969. The mechanisms of burrowing into soft substrata by marine animals. Oceanogr.Mar. Biol. Ann. Rev. 7: 315-366.

Walpole, RE. 1992. Introduction to Statistic 3rd Edition. Diterjemahkan oleh Sumantri B. 
Aspek Pertumbuhan Undur-undur

PT Gramedia Pustaka Utama: Jakarta. 515 hlm.

Wenner, AM. 1988. Crustaceans and other invertebrates as indicators of beach pollution. In: Soule DF, Kleppel GS (Eds.) Marine Organisms as Indicators, pp. 199229. Springer-Verlag, New York. 